\title{
FEAR IN PREGNANCY
}

Daniela Brandão, Filipa Martins Alves, Teresa Novo

Department of Psychiatry and Mental Health, Local Health Unit of Alto Minho, EPE, Viana do Castelo, Portugal.

\section{BACKGROUND AND SCOPE}

The perinatal period represents a period of greater vulnerability to the appearance or aggravation of psychiatric disorders, namely depression, psychosis and obsessivecompulsive disorder (OCD).

OCD during pregnancy or postpartum can often go undetected and, as such, untreated. The most common obsessions, during pregnancy or in the puerperium, are of contamination and aggressive thoughts (such as intentionally or accidentally harming the child), and compulsions associated with cleaning, washing, checking and avoidance. There are no rigorous epidemiological studies, but it is known that women may be at an increased risk during pregnancy or postpartum.

The intervention should be based on the risk of harm to mother or child, and hospitalization may be necessary.

\section{RESULTS}

A 39-year-old-woman, 39 weeks pregnant, observed by psychiatry for obsessive thoughts focused on the baby. Expressed fear of contaminating the baby compulsively washing hands to decrease her anxiety. She was afraid of losing the baby, and after a simple touching on belly, she would go to the emergency department to make an ultrasound to check fetal wellbeing.

She had no personal or psychiatric family history. Antecedents of spontaneous abortion a year ago.

She did not seek help earlier because of shame and fear of being criticized.

She was medicated with fluoxetine and oriented to external consultation of psychiatry, with improvement in the clinical picture.

\section{OBjectives}

To present a case of OCD in pregnant and to review the literature.

\section{Material AND Methoths}

Literature review, using computerized databases (MEDLINE®), UpToDate®). Articles were selected based on the content of their abstract and their relevance.

\section{Conclusions}

OCD in pregnancy or postpartum is a clinical challenge, and the course in these cases is not well studed. Treatment in pregnant and postpartum women is complex with little information available.

Early intervention is essential because it may interfere with the functioning of the mother, and consequently the development of the mother-baby bond. Although mothers are afraid of hurting babies, they usually do not pose a risk to them.Health professionals have an important role in informing women about the symptomatology of OCD and the identification of women at high risk of developing OCD.

\section{REFERENCES}

Brandes M, Soares CN, Cohen LS. Postpartum onset obsessive-compulsive disorder: diagnosis and management. Arch Womens Ment Health. 2004; 7(2):99-110 Munk-Olsen T, Laursen T, Tederson C, et al. New Parents and mental disorders: a population based register study. JAMA. 2006; 296 (21):2582-2589

Uguz F, Akman C, Kaya N, Cilli AS. Postpartum-onset obsessive-compulsive disorder: incidence, clinical features, and related factors. J Clin Psychiatry. $2007 ; 68$ (1): 132-8

Aruadna Forray MD, Mariel Focseneaunu MD, Brian Pittman MS, Christopher MD and Neill Epperson MD. Onset and Exacerbation of Obsessive-Compulsive Disorder in Pregnancy and the Postpartum Period. J Clin Psychiatry. 2010; 71 (8):1061-1068 